ate indeed were the attempts to explain gravitation by means of mechanisms, often belonging in a generul way to the same order of ideas as the vortices proposod enrlior hy Descartes.

While gravitation bulks largest in Prof. Koyré's book, other Newtorian fields (optics and theology, for example) are by no means neglected. 'The reader should not bo put off by occasional passages in which a nervous style becomes arrusing in its qualifications (seo, for example, the long sentence on p. 4 which begins "Besides, all of us, or if not all still most of us, have been born and bred -or better and more exactly, not born (as this is impoksible) but only bred -in the Newtonian or, at least, $n$ semi-Nowtonian world ..."'). The book is valuable both as a compendium of information (including its numerous references and its many quoted passages made moro conveniently accessiblo) and as an acute discussion of the idecs of Newton and his various advorsarics, critics and apologists.

The book is woll produced, the printing is excellent, with fow misprints, and there is a useful index. I should havo welcomed somewhat larger type, especially sinco the footnotes, which may bo described as nover occupying moro than 90 per cent of the page, aro crammed with dotail and often call for caroful reading. A. FLETCHer

\section{FREUD WRITES TO HIS FRIEND}

\section{A Psycho-Analytic Dialogue}

The Letters of Sigmund Freud and Karl Abraham, 1907-1926. Edited by Hilda C. Abraham and Ernst L. Froud. Translated by Bernard Marsh and Hilda C. Abraham. (The International Psycho-Analytical Library, No. 68.) Pp. xvii + 406. (London: The Hogarth Pross, and the Institute of Psycho-Analysis, 1965.) 63s. net.

A PSYCHO-ANALYTIO DIALOGUE is on interest$A$ ing book for those wishing to learn of the earlier happenings in psycho-analysis and the personality of the master and his disciples. It consists of lottors from Freud to Abraham over 19 years, translated by two difforent translators in order to give a feeling of individual style. This has been done so well that the impression is of the originals not having been written in a foreign languago at all.

If a science consists of tho collection of facts, their examination and the meaning deduced from them, and the prediction of further facts as a result, the psychoaxalysis can claim to be a science, or at loast the beginning of one. The only thing which it lacks is measurement, which must depend on better means of estimating emotion.

Freud and Abraham spent long hours every day in clinical work, in listening to patients talking without guidance in free association. Indeed, Freud says in one of his letters that he has beon doing so for 11 hours a day (pago 143) and Abraham for nearly as long. Surely this must bo regarder as similar to the collection of facts in a laboratory? The formulation of theories to explain what was found led to the body of ideas which is the basis of psycho-analysis to-day.

The discovery of methods to investigate the mind, loading somotimes to cure of the disease, and the potontial fiolds rovealed naturally attracted others who were eager to theorize without the trouble of clinical work. This would have lod to a distortion of what Froud folt was tho basis of his work and naturally he set his face against it. In his letters to Abraham ho somotimes releases his irritation for those intruders and expresses his weariness. (This is not surprising when one learns that he was writing books, such as Totem and Taboo, as well as seeing patients all day.)

Froud has sometimes been accused of intrigue, although this seems to bo contrary to his porsonality, but in these letters, when dissidents like Adler, Stekel and Jung arn mentioned, he does not plot against them, except only inasmuch as he wishes them to leave the movoment. Sometimes his language showed his irritation as when he writes of "the brutal sanctimonious Jung", but his efforts are always towards shedding those who will not conform to clinical findings, not their injury.

It would be absurd to protond that there is a great deal which is very profound in these letters. They are the exehange of comment between two rmen, one twenty yoars senior, who are interested in the same work and the same movement. Yet they seem to throw a light on the sort of pooplo they wore and the respect which they felt for each other.

'Ihey begin with the exchange of lotters devoted purely to analytical matters and end on a much more affoctionate note, as if Freud had adopted $A$ braham as a most intimato friend, and Abraham had reciprocated. All through the correspondence there is this friendly note, but Abraham was by no means a mero affirmative to Freud. Indeed, bo disagreed strongly in such matters as the personality of Jung and was oventually proved correct in his estimate. A great deal of the contents of Freud's letters has found its way into the various histories of psycho-analysis, but those interested in the original statements will find it fascinating to know what was occurring and said at the timo. No one will learn completo psycho-analytical theory from them (although some can be gleaned), but as a study of two eminent men thoy are of great interest.

\section{Althen}

\section{BRAIN AND SELF}

The Brain and the Unity of Conscious Experience (The Nineteenth Arthur Stanley Eddington Memorial Lecture, 15 October, 1965.) By Sir John Eccles. Pp. 45. (London: Cambridge University Press, 1965.) 4s. 6d. not; 95 cents.

CIR JOHN ECCLES's Eddington Locture for 196: $O$ entitled The Brain and the Unity of Conscious Experi. ence is a most distinguished addition to the series. Throequarters of it is devoted to brilliant and penetrating survey of the latest neurophysiological evidence linking neuronat activity with the existence of conscious states. Much of the work quoted is as yet unpublished, and very important new advances by Moruzzi, Mountcastle, Libet, Myers and Bremer are outlined. Perhaps particularly outstanding is the recent work of Libet and his colleagues, who have utilized the responses of the sornaesthetic area in an attempt to discover the nature of the neuronal activity that leads to conscious experience. It was found that with all conditions of threshold stimulation there is a delay of at least 0.5 sec before the onset of the experionced sensation-a sort of 'incubation period' of a conscious experience at threshold level. In the visual system also, there is evidence that at least $0.2 \mathrm{sec}$ of cortical activity is required before the first threshold flash of light can be detected. There is also an excellent account of Sporry's work on the experiences and behaviour of human splitbrain patients. This condition in these patients results from the operation of sovoring the corpus callosum, the anterior commissure and the massa intermodia-an operation which has been highly successful in some eases of sovere and long-standing epilepsy.

The final part of the lecture considers whothor the uniqueness of the experiencing self derives from genetic uniqueness. Here, Sir John goes back to some littleknown, but important, speculations by the ominont American biologist, H. S. Jennings, published in 1930. Since identical twins have identical geno combinations he concludes that these combinations must obviously be compatible with distinctiveness of experiencing selves. He thus concludes that the uniqueness of the individual self cannot be due solely to the uniqueness of the individual gone combination. Ho furthor concludes, by what appears to be sound reasoning, that neither oan the 